\title{
Mathematical Modelling of Induction Motor Transient Processes During Stator Winding Interruption
}

\author{
Marina Konuhova, Riga Technical University, Guntis Orlovskis, RTU, Karlis Ketners, Riga Technical University
}

\begin{abstract}
This research presents induction motor mathematical model in coordinate axis's $\alpha, \beta$, which allows to learn transient processes in rotor and stator circuits in the conditions of stator windings opening. Such kind of researches is nowadays actual due to impossibility of main calculated values measuring directly, but only on the stator terminals. Induction motor mathematical model forms Park-Gorev equations in $\alpha, \beta$ coordinate axis. It is preferable to use this coordinate system because it allows comparing the results of mathematical modeling in one of the phases with experimental data without transformations.
\end{abstract}

Keywords: induction motor, mathematical model, rundown regime, transient processes.

\section{INTRODUCTION}

Squirrel cage induction motors (IM) are simpler in structure than DC motors and are most commonly used $n$ the VSD industry. They are robust and reliable. They require little maintenance and are available at very competitive prices. They can be designed with totally enclosed motors to operate in dirty and explosive environments. Their initial cost is substantially less than that of commutator motors and their efficiency is comparable. All these features make them attractive for use in industrial drives [1].

In crucial consumers, which rotation is activated by IM interrupted operation provides power sources quick switch over. Every IM switching is accompanied by rundown regime $[2,3]$. It looks that the processes of rundown regime, especially rotation speed characteristics are reviewed in technical literature in details, taking into account that it is effected by machine internal parameters and load coefficient and load characteristics [2].

Rundown regime is accompanied not only by machine rotor rotation speed, but stator windings remaining voltage attenuation after power supply interruption as well.

IM rundown regime attracts the interest because of the processes could happen in inimical conditions of opening might lead to significant current strokes and short term extreme mechanical forces in the case of repeated closing during stator magnetic field still not attenuated and that is dangerous for IM [4]. It was not made deep investigations before regarding such an obstacles as far present automation devices had minimum breaking time longer, than remaining EMF attenuation time.

Nowadays, in the innovative fast-operating automation devices use, closing time dropped up to $0.005 \mathrm{~s}$ [5]. But at that time IM even small capacity breaking stator windings power supply does not succeed remaining voltage decrease up to safe value. Therefore, if made repeated closing with presence of remaining EMF and in case of opposite phase, the current stroke significantly exceeds start-up current value and that is dangerous for IM.

For the actual moment there is topical different kind of investigations connected to the processes acting in induction motor rotor circuit $[6,7]$.

The aim of this investigation in connection with above described is IM mathematical model development, opening the opportunity to search the processes running in IM rotor circuit in rundown regime.

\section{FEATURES Of INDUCTION MOtOR RUNDOWn REGIME.}

After IM switching off power supply the current in stator disappear, but magnetic flow in machine remains on account of current alteration in closed rotor winding. Deeming squirrel-cage rotor winding for the switching moment superconductive and using for it the principle of flux linkage steadiness, we deem that rotor flux linkage when stator current disappear remains the same as antecedent stationary regime in the beginning of power switching off. On the stipulation of stationary of rotor flux linkage, we calculate the rotor currents during rundown regime.

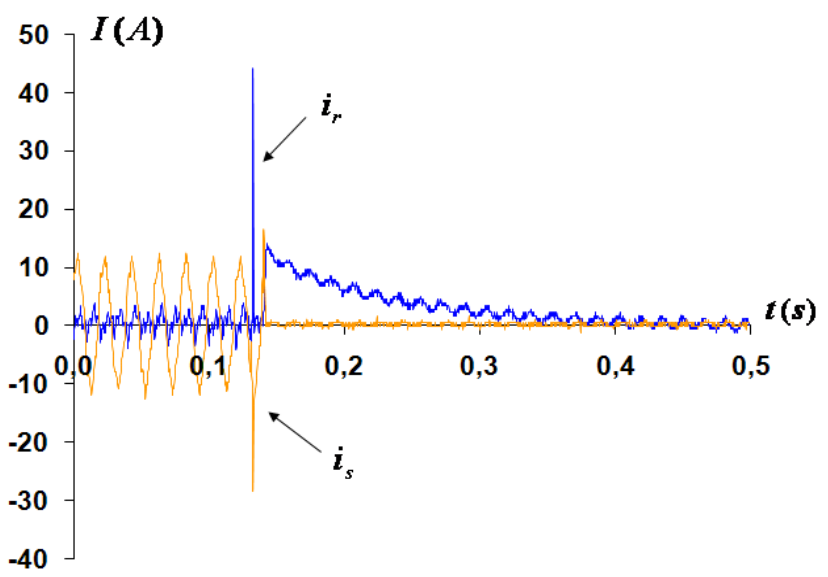

Fig.1. IM with phase-wound rotor rotor and stator currents oscillograms in rundown regime.

For the IM with phase-wound rotor in the idle running regime, after run up, rundown process on the oscillograph shown current stroke (Fig.1).

For the research of the processes in IM with squirrel-cage rotor it was developed mathematical model, based on Park- 
Gorev equations. This model allows to model processes in rotor circuit of IM with squirrel-cage rotor at the moment of switching power off.

\section{INDUCTION MotoR MATHEMATICAL MODEL.}

The IM mathematical model description in a,b,c coordinate system (phase coordinates) most completely reflects working processes physical picture. Yet periodically altering coefficients big portion and the member of processes influencing model parameters like working temperature alteration, impregnation influence etc hinders such a model usage [8].

Thus most wide used abstract and simple models, which used to call generalized electrical machines.

Resulting voltage vectors equations related to rotating with arbitrary speed $\omega_{k}$ coordinate axis represents the simplest and common kind of Kirchhoff equations for generalize machine

$$
\left.\begin{array}{l}
\mathbf{U}_{s}=R_{s} \mathbf{I}_{s}+\frac{d \psi_{s}}{d t}+j \omega_{k} \psi_{s} \\
\mathbf{U}_{r}=R_{r} \mathbf{I}_{r}+\frac{d \psi_{r}}{d t}+j\left(\omega_{k}-\omega_{r}\right) \psi_{r}
\end{array}\right\}
$$

Such a kind with arbitrary speed $\omega_{k}$ equations are not used often [6]. The most interest taken to equations in coordinate axis $\alpha, \beta$ when $\omega_{k}=0$, and in coordinate axis $d, q$, when $\omega_{k}=\omega_{\text {sinh }}$.

$\omega_{k}$-angular rotation speed of coordinate system.

For the fixed coordinates $\alpha, \beta \quad\left(\omega_{k}=0\right)$, when axis linked to stator, the equations for squirrel-cage rotor motor allowed for derivative flux linkages become following:

$$
\left.\begin{array}{c}
\frac{d \psi_{s \alpha}}{d \tau}=U_{m} \cdot \cos (\tau)-R_{s} \cdot i_{s \alpha} ; \\
\frac{d \psi_{s \beta}}{d \tau}=-U_{m} \cdot \sin (\tau)-R_{s} \cdot i_{s \beta} ; \\
\frac{d \psi_{r \alpha}}{d \tau}=-R_{r} \cdot i_{r \alpha}+\omega_{r} \psi_{r \beta} ; \\
\frac{d \psi_{r \beta}}{d \tau}=-R_{r} \cdot i_{r \beta}+\omega_{r} \psi_{r \alpha} ;
\end{array}\right\}
$$

Where the current values calculated by following equations of flux linkages:

$$
\left.\begin{array}{l}
i_{s \alpha}=\left(X R \cdot \psi_{s \alpha}-X A D \cdot \psi_{r \alpha}\right) / d e l ; \\
i_{s \beta}=\left(X R \cdot \psi_{s \beta}-X A D \cdot \psi_{r \beta}\right) / d e l ; \\
i_{r \alpha}=\left(X S \cdot \psi_{r \alpha}-X A D \cdot \psi_{s \alpha}\right) / d e l ; \\
i_{r \beta}=\left(X S \cdot \psi_{r \beta}-X A D \cdot \psi_{s \beta}\right) / d e l
\end{array}\right\}
$$

where $d e l=X S \cdot X R-X A D \cdot X A D$

$$
M_{e m}=X A D\left(i_{s \alpha} \cdot i_{r \beta}-i_{s \beta} \cdot i_{r \alpha}\right)
$$

$$
M_{l}=S M \cdot \omega_{r}^{2}+S M K
$$

where $\psi_{1 \beta}, \psi_{1 \alpha}, \psi_{2 \beta}, \psi_{2 \alpha}$ - stator and rotor components of flux linkages;

$i_{s \alpha}, i_{s \beta}, i_{r \alpha}, i_{r \beta}$ - stator and rotor currents components;

$\omega_{2}$ - angular rotation speed of rotor;

$U_{m} \cos (\tau),-U_{m} \sin (\tau)$ - voltage supplied to stator windings;

$R_{s}, R_{r}, X_{s}, X_{r}$ - induction motor parameters;

$M_{e l}, M_{l}$ - torques electromagnetic and of load;

$T_{M}$ - machine time constant measured in electrical radians;

$X R, X S, X A D$ - induction motor parameters measured in related units.

Using provided equations (2-3) it is modeled IM start up mode and repeated switching mode.

For IM rundown mode modeling we mark parameters of IM at the switch off moment as steady during start up $\psi_{r \alpha 0} ; \psi_{r \beta 0} ; \omega_{0 r} ; i_{r \alpha 0} ; i_{r \beta 0}$.

Forced equalization to zero of stator current (7) leads to change of rotor currents $i_{r \alpha} ; i_{r \beta}$ from the terms of retention of flux linkage vector constant at switching moment.

$$
i_{s \alpha 1}=0 ; i_{s \beta 1}=0
$$

During IM rundown mode its functioning describes following differential equations system:

$$
\left.\begin{array}{c}
\frac{d \psi_{r \alpha 1}}{d \tau}=-R R \cdot i_{r \alpha 1}+\omega_{r 1} \psi_{r \beta 1} \\
\frac{d \psi_{r \beta 1}}{d \tau}=-R R \cdot i_{r \beta 1}+\omega_{r 1} \psi_{r \alpha 1}
\end{array}\right\}
$$

It is possible to get the curves reflecting alterations of currents, flux linkages, voltages on the rundown time at stator and rotor circuits using provided model.

Comparing them with experimental data should be noted that the IM regimes mathematical modeling in $\alpha, \beta$ coordinate system is favorable because of opportunity to compare one phase results without additional transformation.

\section{MODELING RESUltS.}

On the base of IM mathematical model presented in previous chapter it was modeled regimes of start up, rundown and repeated switching of induction motor with following parameters (in related units): $X_{S}=5.799, X_{r}=5.84$, $X \mu=5.7, R_{S}=0.012, R_{r}=0.027$. 


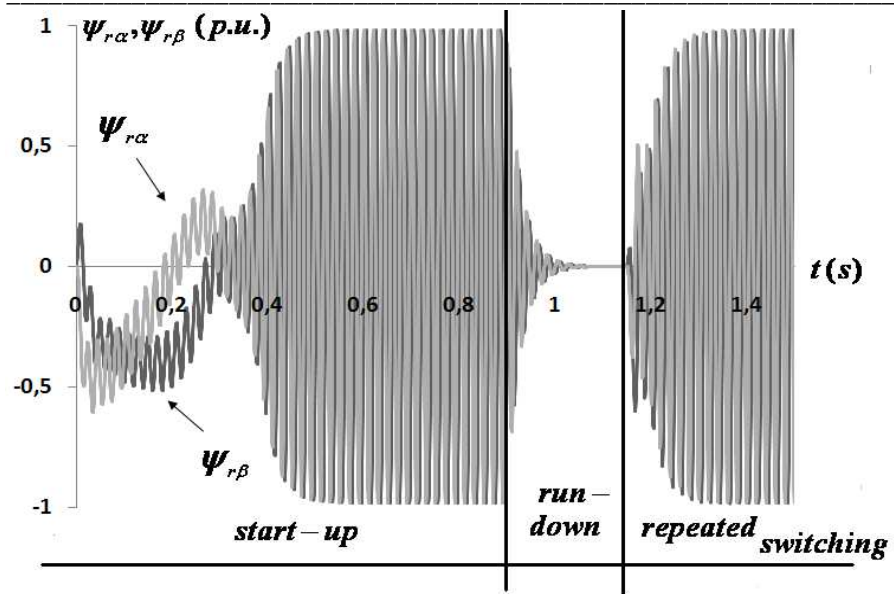

Fig.2. IM rotor flux linkage on start up, rundown and repeated switching alteration curves.

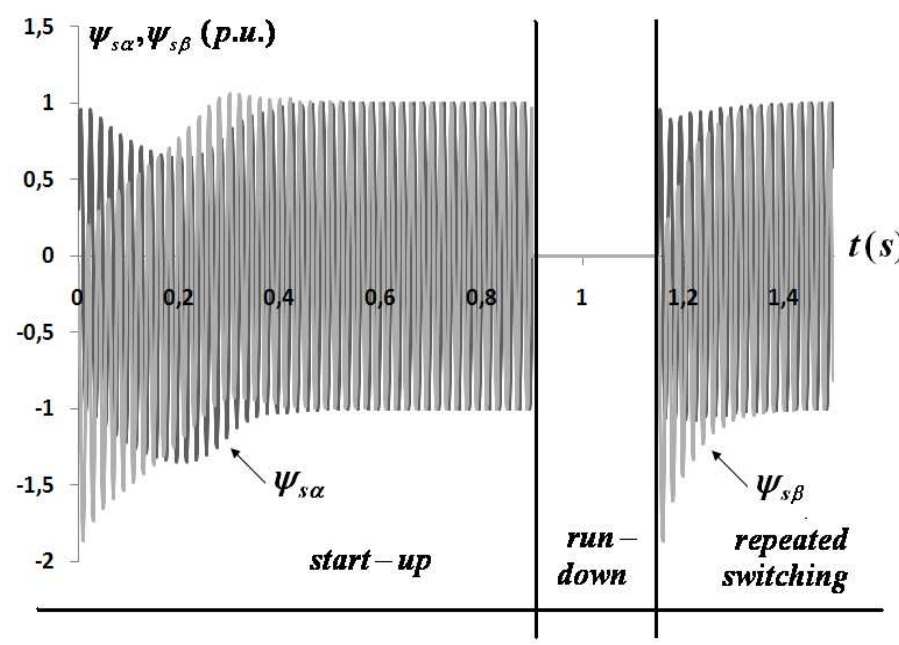

Fig..3. IM stator flux linkage on start up, rundown and repeated switching alteration curves.

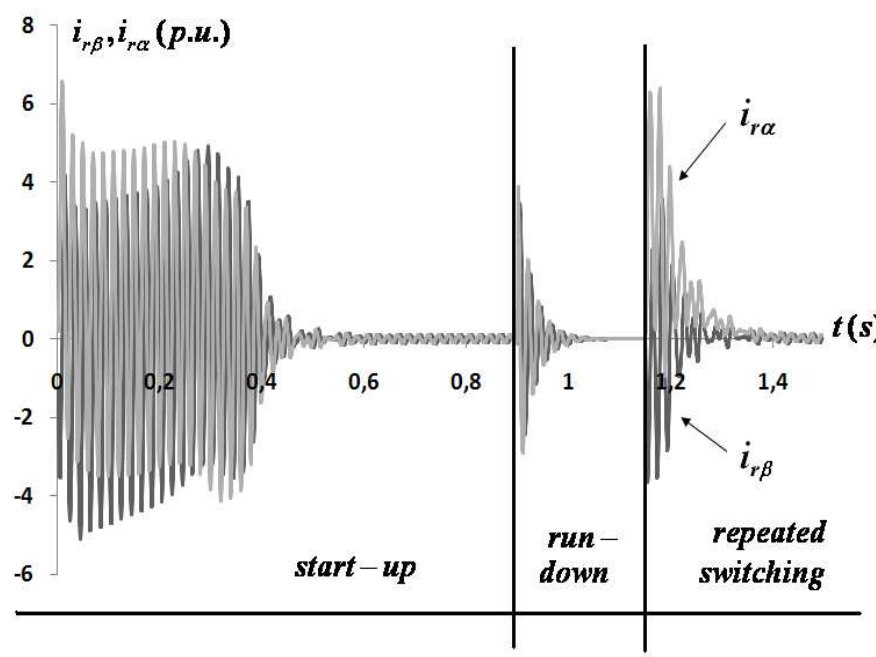

Fig..4. IM rotor currents on start up, rundown and repeated switching alteration curves.

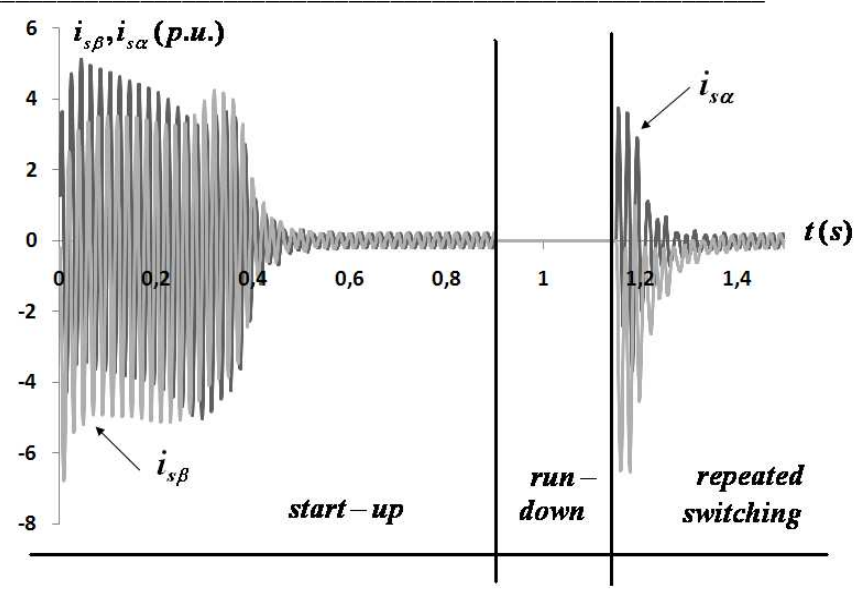

Fig.5. IM stator currents on start up, rundown and repeated switching alteration curves.

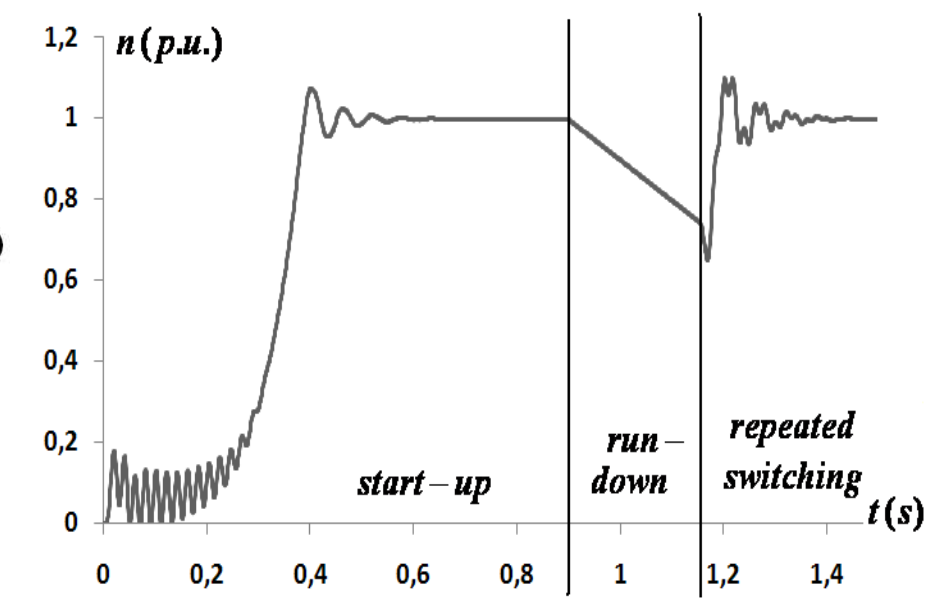

Fig.6. IM rotation speed on start up, rundown and repeated switching alteration curves.

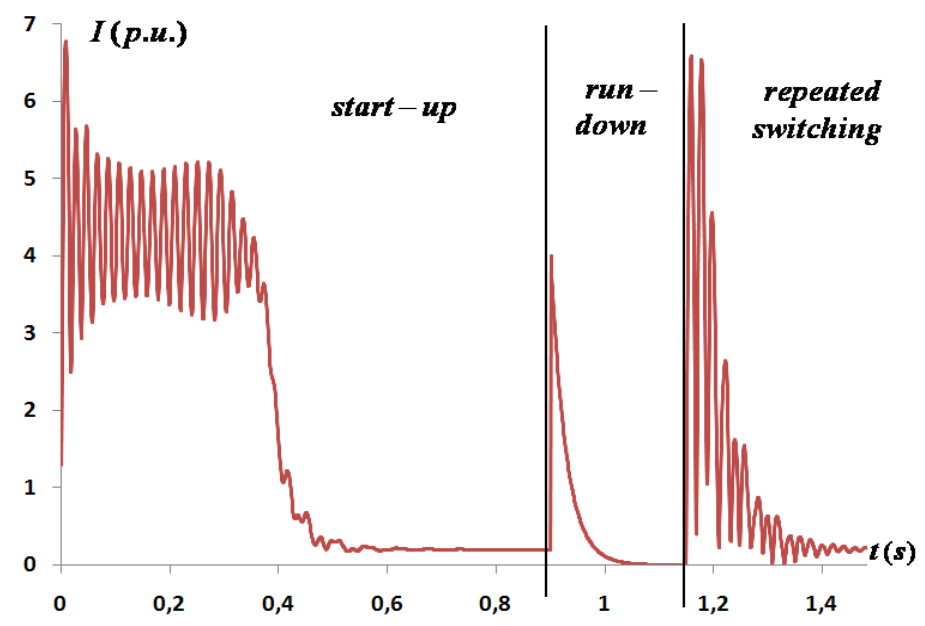

Fig.7. IM current on start up, rundown and repeated switching alteration curves. 


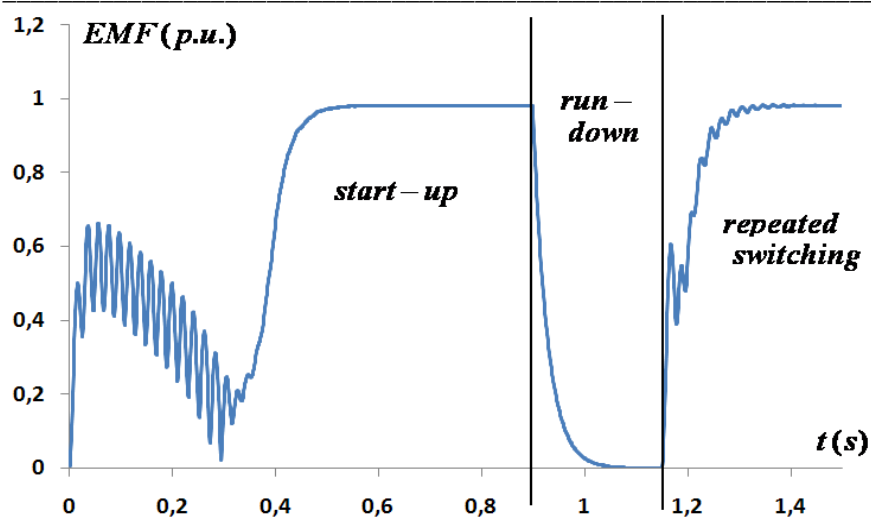

Fig.8. IM EMF on start up, rundown and repeated switching alteration curves.

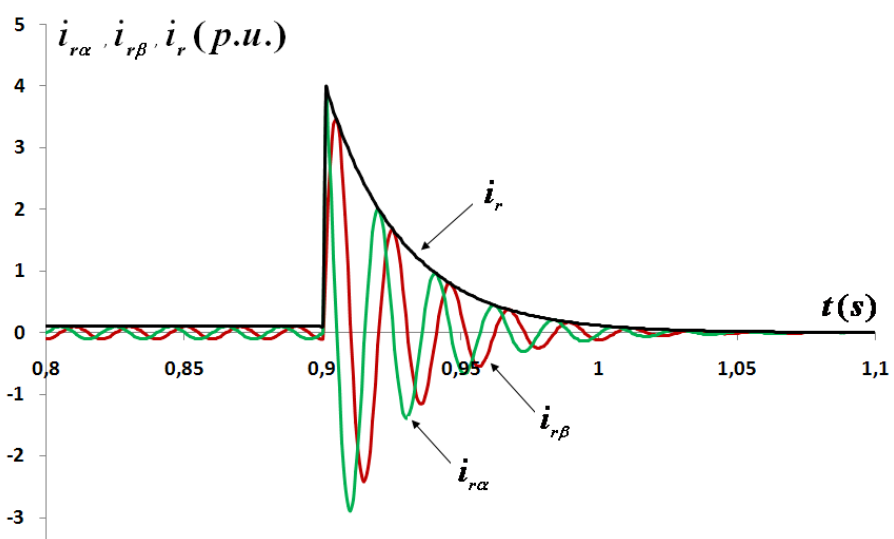

Fig.9. Squirrel cage IM rotor currents on rundown alteration curves.

With the purpose of provided model adequacy examination it was made comparison of modeling and experimental research results. It was found out that the IM with phase-wound rotor current curve got on oscillograph for the rundown regime (Fig.1) correspond to current curve of IM with squirrel-cage rotor, received using mathematical model for the same regime (Fig.9).

\section{CONCLUSIONS}

Provided IM mathematical model in $\alpha, \beta$ coordinate axis allows to research transient processes happening on stator windings circuit break.

Mathematical modeling of IM operating regimes in $\alpha, \beta$ coordinate axis preferable because it gives opportunity to compare results on one phase with experimental data without additional transformations.

As a result of mathematical modeling of rundown regime came clear that in rotor circuit at the moment of IM switching off rotor current booms and in the rundown process with time constant of the rotor circuit decreases up to zero. This current alteration inducts EMF, phase and summarizing it with power source voltage may negatively effect IM on fast repeated switching on.

The processes in rotor circuit for the IM with squirrel-cage rotor in rundown regime are similar with processes in rotor circuit in IM with phase-wound rotor.

\section{ACKNOWLEDGMENT}

This work has been supported by the European Social Fund within the project ,Support for the implementation of doctoral studies at Riga Technical University”.

\section{REFERENCES}

[1] M.H.Rashid. Power Electronics Hand book, second edition, Elsevier Inc. 2007.

[2] Сыромятников И. А. Режимы работы асинхронных и синхронных электродвигателей./под. Ред. Л. Г. Мамиконянца.-4-е изд. перераб. И доп.:-М.: Энергоатомиздат, 1984.-240.

[3] Важнов А.И. Электрические машины. Л. «Энергия» 1968.- 768.с.

[4] Konuhova M., Ketners K., Ketnere E., Kluevska S. „Investigation of the undamped field effect to the electromagnetic processes in the induction machines". RTU. "Energétika un elektrotehnika" 4. Sērija, 25. Sējums, Rīga, 2009.

[5] Терехов В.М. Системы управления электроприводом: Учебник для студ. Высш. Учеб. Заведений/ В.М.Терехов, О.И. Осипов; Под ред. B.M.Терехова.-М.: Издательский центр «Академия», 2005.-304 c.

[6] G.R. Slemon, "Modeling Induction Machines for Electric Drives", IEEE Trans. on Industry Applications, Vol.25.No.6.pp.1126-1131.Nov.1989.

[7] R.K. Rajpuk, Electrical Machines, first edition. New York: McGrawHill, 1993, pp.352-353.

[8] P.Drozdovski, T.J.Sobcryk."On a mathematical model of squirrel-cage induction motors", Electrical Engineering, Springer Berlin, Vol.70, No.6. pp.371-382, Nov, 1987.

[9] Копылов И.П. Математическое моделирование электрических машин: учеб. для вузов.-3-е изд. перераб. и доп.- М.: Высш.шк., 2001.-327 c.

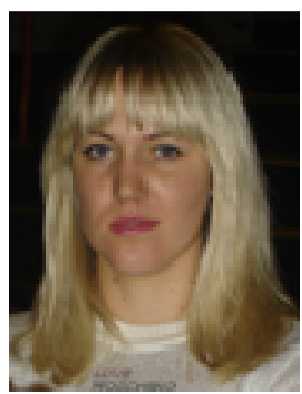

Marina Konuhova

Mg.Sc.Ing., PhD student

Riga Technical University,

Power Engineering Institute

Adress: Kronvalda blv. 1, LV-1010, Riga, Latvia

Phone: +371 29691890, fax 67089418

Email: Marina.Konuhova@rtu.lv

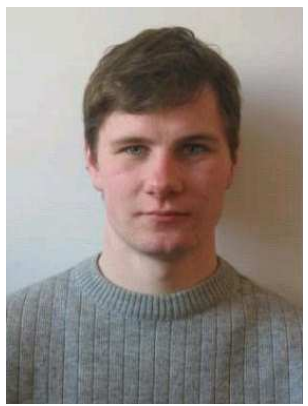

Guntis Orlovskis,

Bak.Sc.Ing., Mg. student

Riga Technical University,

Power Engineering Institute

Address:Kronvalda blv., 1, LV-1010, Riga,

Latvia

Phone: +3717089927

Email: jott@inbox.lv

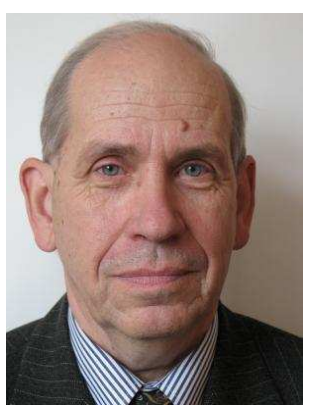

Karlis Ketners

Professor, Dr.Sc.Ing.

Riga Technical University,

Power Engineering Institute

Adress: Kronvalda blv. 1, LV-1010, Riga, Latvia

Phone: +371 67089926, fax 67089418

Email: ketners@eef.rtu.lv 